\title{
Intermediate Level Learners' Vocabulary Guessing and Recognizing through Sound Symbolism
}

\author{
Mohammad Zohrabi (Corresponding Author) \\ English Department, Faculty of Persian Literature and Foreign Languages \\ University of Tabriz, Tabriz, Iran \\ E-mail: mohammadzohrabi@gmail.com \\ Hossein Sabouri \\ English Department, Faculty of Persian Literature and Foreign Languages \\ University of Tabriz, Tabriz, Iran \\ E-mail: kassabouri@gmail.com \\ Saeid Peimanfar \\ Islamic Azad University \\ Tabriz Branch \\ E-mail: speymanfar@yahoo.com
}

Received: 27-04-2014

Accepted: 18-06-2014

Published: 01-11-2014

doi:10.7575/aiac.ijalel.v.3n.6p.42

URL: http://dx.doi.org/10.7575/aiac.ijalel.v.3n.6p.42

\begin{abstract}
Research into vocabulary acquisition indicates that there are several contributors to word learning. However, the question of phonology's place in word learning has been virtually ignored. Sound symbolism is the idea that the relationship between phonology and semantics is not always arbitrary and that for some words present in today's languages there is correspondence between sound and meaning. The impetus behind the present study was to investigate whether sound symbolism as a possible route leads to increased word learning. The study compared the guesses that 90 intermediate level Turkish learners of EFL made regarding the potential meanings of sound symbolic and non-sound symbolic words both in the presence and absence of context. Independent sample t-tests were calculated to analyze the participants' guesses of the word meaning. The results revealed that the participants were able to guess the meanings of sound symbolic words significantly better than the meanings of non-sound symbolic words. The analysis of independent sample t-test substantiated that both sound symbolism as a word level property and context are significantly effective for word learning. As the results revealed, when sound symbolic words were embedded in their relevant written context, the participants' guesses were the highest. That is, the interactive efficacy of sound symbolism plus context was significantly higher than the efficacy of either of them. Hence, EFL teacher may raise the learners' awareness to sound symbolism as a potential means in restricting and interpreting the meaning of unknown words.
\end{abstract}

Keywords: sound symbolism, word learning

\section{Introduction}

It is common sense that without words there can be no proper communication, however basic (Laufer, 1997). Vocabulary is a core component of language proficiency and provides much of the basis for how well learners speak, listen, read and write (Nation, 2002). It is common sense that, words and multi-words are considered as the building blocks of verbal communication (Elgort \& Nation, 2010).

The task of word learning is an essential progress in children's lives. It is also important for communication in a foreign language. Virtually all second language learners and their teachers are well aware of the fact that learning a second language (L2) involves the learning of a large number of words (Hulstijn \& Laufer, 2001). Vocabulary teaching and learning is deemed to be central to the theory and practice of ELT (Carter, 2001).

Without an extensive vocabulary and strategies for acquiring new vocabulary, learners often achieve less than their potential and may be discouraged from making use of language learning opportunities around them. Even a cursory comparison of the vocabulary knowledge of native speakers of English and EFL learners reveals the gap between the vocabulary of EFL learners and that of native speakers of English. The marked difference between native speakers and non-native speakers' vocabulary knowledge is in itself a reason enough for investing teaching efforts into the vocabulary development of second language/ foreign language learners. Vocabulary size has been shown to be the best predictor of reading comprehension in L1 and L2 (Laufer, 1991). Moreover, vocabulary correlates highly with global assessment of writing quality and with general language proficiency scores (Astika, 1993; Engber, 1995). Therefore, the importance and the prominence of vocabulary learning and vocabulary teaching for ESL and EFL learners is clear. 
The overall objective which the authors aspired to accomplish through this study was to find out whether sound symbolism as a majorly linguistic phenomenon has any educational and pedagogical place in the realm of vocabulary acquisition. It is to examine the possibility that sound symbolism may have a role in word learning. Inasmuch as intermediate learners of EFL should develop appropriate vocabulary learning skills, the authors would like to investigate whether they can use sound symbolism as a word property for guessing the semantic meaning of words.

The impetus beyond running this research study was to investigate the value of a hunch about sound symbolic word learning; that hunch can be narrowed down and formulated into the following specific research questions and hypotheses.

1- Do intermediate EFL learners guess the meaning of unknown sound symbolic words significantly better than the meaning of unknown non-sound symbolic words when they are isolated from surrounding written context?

$\mathrm{H}_{0}$ : Intermediate EFL learners do not guess the meaning of unknown sound symbolic words significantly better than the meaning of unknown non-sound symbolic words when they are isolated from surrounding written context.

$\mathrm{H}_{1}$ : Intermediate EFL learners guess the meaning of unknown sound symbolic words significantly better than the meaning of unknown non-sound symbolic words when they are isolated from surrounding written context.

2- Do intermediate EFL learners guess the meaning of unknown sound symbolic words significantly better than the meaning of unknown non-sound symbolic words when they are embedded in and surrounded by context?

$\mathrm{H}_{0}$ : Intermediate EFL learners do not guess the meaning of unknown sound symbolic words significantly better than the meaning of unknown non-sound symbolic words when they are embedded in and surrounded by their context.

$\mathrm{H}_{2}$ : Intermediate EFL learners guess the meaning of unknown sound symbolic words significantly better than the meaning of unknown non-sound symbolic words when they are embedded in and surrounded by their context.

3- Does sound symbolism as a hypothetical word property interact with context so as to provide intermediate EFL learners with a significantly richer clue than that merely provided by context for guessing the meaning of sound symbolic words?

$\mathrm{H}_{0}$ : Sound symbolism as a hypothetical word property does not interact with context so as to provide intermediate EFL learners with a significantly richer clue than that merely provided by context for guessing the meaning of sound symbolic words.

$\mathrm{H}_{3}$ : Sound symbolism as a hypothetical word property interacts with context so as to provide intermediate EFL learners with a significantly richer clue than that merely provided by context for guessing the meaning of sound symbolic words.

\section{Review of Related Literature}

\subsection{Sound Symbolism}

The relationship between sound and sense is predicated by the notion of sound symbolism. Sound symbolism is the study of the relationship between the sound of an utterance and its meaning. For decades it has been thought that the link between sound and meaning is arbitrary. In spite of the much-acclaimed Saussurean principle of the arbitrariness of the linguistic sign, linguists have always been aware that all languages exhibit sound symbolic effects violating this principle. However, evidence for sound symbolism is typically anecdotal. For example, onomatopoeia is a prime example of this exception. Sound symbolism maintains a challenge to the privileging of the arbitrariness of the linguistic sign in structuralist linguistics. "The term sound-symbolism is used when a sound unit such as a phoneme, syllable, feature, or tone is said to go beyond its function as a contrastive,non-meaning-bearing unit, to directly express some kind of meaning" (Nuckolls, 1999, pp. 228). Sound symbolism has the following general characteristics:

- Sound symbolism is fundamental to language.

- Sound symbolism is both inside and outside of language.

- Sound symbolism is productive.

- Sound symbolism is universal.

A scale can be set up between sound symbolic utterances and completely conventional, arbitrary language where sound and meaning presumably have no direct relationship (Hinton et al., 1994). It is reasonable to categorize the overall concept of sound symbolism into the following different types:

Corporeal sound symbolism. It refers to the use of certain sounds or intonation patterns to express the internal state of the speaker, emotional or physical. It includes involuntary symptomatic sounds such as coughing or hiccupping and ranges through expressive intonation, expressive voice quality and interjections (Hinton et al., 1994).

Imitative sound symbolism. It relates to onomatopoeic words and phrases representing environmental sounds (e.g., bang, bow-wow, swish, knock and rap). Imitative sound symbolism includes many utterances that utilize sound patterns outside conventional speech and are difficult to portray in writing. Imitative sound symbolic is much better represented in the linguistic literature than corporeal sound symbolism (Hinton et al, 1994).

Synthetic sound symbolism: It is the process whereby certain vowels, consonants and suprasegmentals are chosen to consistently represent visual and tactile properties of objects such as size and shape.

Conventional sound symbolism: This typology refers to the analogical association of certain phonemes and clusters with certain meanings; e.g., the gl of glitter, glisten, glow, glimmer, etc. (Hinton et al., 1994).

Metalinguistic sound symbolism: Cross-cutting the above categories are a sort of sound symbolism that might be termed metalinguistic symbolism where segment choice and intonation patterns signal aspects of linguistic structure and 
function. It represents the exclusion of or preference for particular phonemes in particular parts of speech or affixes (Austerlitz et al, 1994).

The above-mentioned categories show the in-depth interest and research into sound symbolism. However, exhaustive discussion and analysis of each of the above-mentioned typologies fall beyond the purpose and scope of the present study and hence the interested reader may consult the referred literature for further details.

The central theme which is tested and drawn upon in the present study is that meaning and sound can never be fully separated and linguistic theory ought to adapt and accommodate itself to that increasingly obvious fact. Sound symbolism can be divided into three types:

- Onomatopoeia

- Expressive interjections

- $\quad$ Sound symbolic phonesthemes

2.2 Sound Symbolism as a Cross-Disciplinary Area of Study

Sound symbolism is a topic of cross-disciplinary interest enjoying contributions from the fields of linguistics, anthropology, literature, biology, and even medicine (Abelin, 1999). In medicine, we find that the corporeal soundsymbolic utterances, especially involuntary cries, can provide physicians with cues about the physical problems of a patient. In biology, we find the ethological (physiological) basis of sound symbolism. In literature, the sound of the words chosen to portray meaning comes to play an important role. Anthropological facet of sound-symbolism is interested in how people of different cultures categorize the world around them. In the discipline of linguistics, the leading question is how much the form of language can be tied to meaning. As a result, it might be argued that sound symbolism is a matter of interest for the above-mentioned disciplines and is shared among them. The findings of different disciplines on the nature of sound symbolism can be integrated to come up with a rich and robust theory of sound symbolism not only in linguistic studies but also in language acquisition.

Cross-linguistic aspects suggest that sensitivity to the sound-meaning correspondences is not entirely the result of conventional mappings learned by speakers of a particular language (Berlin, 1994). As a case in point, for example, Kunihira (1971) reported that when native English speakers were presented with Japanese antonym pairs (e.g., "ue" and "shita") and their English translations (e.g., "up" and "down"), they were able to match the two antonyms with the correct English translations. This type of cross-linguistic matching suggests that some aspect of the sound properties of unfamiliar words systematically relates to meaning and that language users recognize this correspondence.

\subsection{Universal Sound Symbolism}

An important issue related to sound symbolism is whether sound symbols are universal or language specific (Hinton et al, 1994). Universal sound-symbolism refers to sound-symbolism recognized by speakers of different languages. Two universal and well-documented cases of sound-symbolism are referred to as distance (spatial) symbolism and size symbolism (Sereno, 1994). The notion of distance symbolism must be considered within the broader framework of deixis. Deixis refers to those features of the language which reflect the spatio-temporal coordinates of the relative situation of the utterance. In an analysis of 136 languages, Ultan (1978) found that $33.1 \%$ of the sample exhibited distance (spatial) symbolism in their demonstrative system. More importantly, the languages that overtly symbolized distance relationships predominantly used front or high front vowels to represent proximity to the speaker. Ultan (1978) also found universal correspondence for size symbolism in language. Some languages overtly mark words expressing diminution by changing the phonological feature of the sound in the root. Ultan found that $27.3 \%$ percent of the 136 languages he sampled had diminutive marking. In almost $90 \%$ of these languages, the diminutive was symbolized by high front vowels. The widespread distribution of these consistently recurring patterns of sound symbolism suggests that the relation between sound and meaning in language is not completely arbitrary. There are two main categories of studies investigating universal sound-symbolism:

- $\quad$ Studies using real words

- $\quad$ Studies using novel words

Research studies on real word experiments can be further divided into the following groups:

○ studies using antonym-pair paradigm

- Studies using real words-non-antonyms

The basic principle of the studies conducted on the antonym-pair matching procedure is that participants are presented with English antonym pairs and antonym pairs in a foreign language or were presented with antonym pairs in two foreign languages. The participant's task is to match the English words to the foreign words, or the foreign to foreign words in terms of meaning. In studies based on real words-non-antonyms procedures, English speaking participants were able to understand real Japanese mimetic words for laughing.

Novel words: Imai et al. (2008) found Japanese and English speakers have the same sound symbolism for actions. The stimuli for Imai et al.'s (2008) study consisted of novel sound-symbolic words for actions. The novel words were derived from existing Japanese mimetics. Participants were asked to rate the degree of match between the novel words and the videos of actions presented. They found support for universal sound symbolism. In sum, it can be argued that a significant body of research supports the universal hypothesis of sound symbolism. 


\section{The Study}

\subsection{Participants}

The required data for answering the research questions of this study were elicited from a sample of intermediate-level learners of English as a foreign language. The rationale for selecting intermediate-level EFL learners as the sample participants of the study was that the majority of the population of EFL learners in the context of study (Iran) are at the intermediate level of proficiency and the population of elementary or advanced EFL learners is far less than that of intermediate learners and hence a sample of intermediate EFL learners represents the population better than learners of other proficiency levels. Furthermore, the probability that the selected materials would have novelty for intermediate learners is higher than that for advanced learners. That is, for testing the hypothetical role of sound symbolism for word learning, the researchers had to include unknown sound symbolic words and the selection of higher level learners could have risked the novelty criterion of the materials and the internal validity of the study.

Two classes of EFL learners were eventually included in this study. A total of 90 participants made up the sample of the study. There were 48 participants in the first intact class and 42 participants in the second intact class. The sample was derived from the population of university students at Islamic Azad University of Tabriz, Iran. At the time the experiments were carried out, they had enrolled in an obligatory general English course. All of the participants were freshmen at Azad University of Tabriz. The participants majored in chemical and mechanical engineering. Their age ranged from at least 18 to at most 26 years old. All of them spoke Turkish as their L1 and studied English as a foreign language. They had Iranian nationality. Since gender was not a variable of focus in the study and inasmuch as the intact classes were regular co-educational classes of the university, there were both male and female participants in the intact groups of the study.

\subsection{Materials}

The Cambridge placement test was used to specify the proficiency level and check the homogeneity of participants within and between the two groups. The aim of using this test was to find an appropriate sample of participants for the study. This objective proficiency test had three sections as follows: listening, reading, and grammar and language use. In total, there were 70 questions in the test and the assigned time for answering the questions was 50 minutes. In section one, there were nine conversations and one or more questions about each conversation. Section two had several short Reading Passages. Multiple-choice comprehension questions followed each passage. Section three had thirty multiple choice items on grammar and language use.

The Cambridge Proficiency test was designed to grade the proficiency level of the participants into different levels. That is to say, there was a range for each proficiency level and if the participants' test results fall within this range (3040), they could be regarded as intermediate learners of EFL.

Having used the Cambridge placement test for selecting the participants of the study, the researchers applied one tool for selecting and checking the novelty of the materials (unknown sound-symbolic and non-sound symbolic vocabulary) for the selected participants. Dale et al's (1986) checklist was used to rate the degree of novelty of stimuli for the selected participants. The purpose for using this scale was to eliminate the vocabulary for which the participants had prior knowledge. It should be mentioned that the scale was used for both non-sound symbolic stimuli and sound symbolic vocabulary. The participants were asked to rate their knowledge and degree of awareness of the meaning of the words into one of four levels. It included four levels of word knowledge as follows:

- I never saw it before.

- I have heard of it before but I don't know what it means.

- I recognize it, it has something to do with .........

- I know it.

The participants were required to rank their knowledge of the given words based on the above-mentioned scale. Indeed, this scale was used to examine if the selected lexical items were novel and unfamiliar for them. In case they had familiarity with the given lexical items, their knowledge would be determined by one of the four choices and the familiar words were eliminated from the list of words and unknown and unfamiliar words would replace them. In order to facilitate the participants' task in rating the checklist, the authors translated the checklist into learners' official language (Farsi).

Questionnaire: Furthermore, in order to investigate the sample EFL participants' attitudes and preferences for using sound symbolism and context, the researchers designed a 10-item-questionnaire to explore the learners' opinion in making use of the phonological structure of words in decoding their meaning. The questionnaire was designed to examine the participants' attitudes and preferences for using the phonological make-up of words and context for guessing the meanings of words. It was written in learners' official language (Farsi). The rationale for the development of the questionnaire in Farsi was that using the official medium of communication could facilitate the task of data elicitation from the participants. Furthermore, inasmuch as the participants were intermediate learners of EFL, they could have trouble understanding and answering the questionnaire in English.

The questionnaire was a 4-point Likert scale in which the participants indicated their preference by checking one of the four choices for each question. The developed questionnaire was piloted on similar intermediate participants before it were given to the target sample. A measure of internal consistency of the items as the reliability of the questionnaire was calculated. 


\subsection{Study Stimuli}

Two different groups of unknown words were included in the study stimuli. Indeed, there were not any specific instructional interventions in this study. That is to say, the researchers did not give any specific treatment to teach the selected unknown lexical items. As a matter of fact, it was attempted to examine the differential learnability of the sound symbolic and non-sound symbolic words for the participants of the study.

\subsubsection{Sound symbolic words}

Fifteen unknown words were selected in which the relationship between the meaning and the sound of the words were not arbitrary. In these selected words, there was a correspondence between the meaning and the sound structure of the words. The aim of using these words as the target of instruction was to examine whether the participants of the study could guess the meaning of the words on the basis of their sound structure. The selected sound symbolic words were unknown and novel to the participants of the study which were selected based on Dale et al' scale of word knowledge. These words were presented to the participants in two different forms: in isolation and surrounded by relevant written context.

\subsubsection{Non-sound symbolic words}

In addition to the 15 unknown sound symbolic words, 15 unknown non-sound symbolic words were included as the learning targets for the participants. Non-sound symbolic words refer to those lexical items in which the relationship between the meaning and the sound of the words is arbitrary and there is no correspondence between them. The purpose for using non-sound symbolic novel words was to compare learners' guessing capability of two types of unknown words, i.e. the presence and absence of sound symbolism as a potential feature of lexical items. Like sound symbolic words, non-sound symbolic words were presented in two ways: in isolation and surrounded by relevant written context.

\subsection{Rating Novelty of the Stimuli}

Having selected two classes with 48 and 42 participants on the basis of the given proficiency test, the researchers ran the first phase of the study. In other words, after the administration of the proficiency test during the first session, the researchers carried out the second phase of the research in the following session. That is, the researchers distributed the translated version of the Dale et al' 1986 scale to the intact classes. The researchers wanted to ascertain that the selected stimuli, both sound symbolic and non-sound symbolic words, were novel and unknown to the participants. The scale provided an examination of the participants' prior knowledge or lack of knowledge of the selected word list so that it provided degree of the participants' awareness of the meanings of words. Indeed, the principal purpose for using this scale was to scratch out the familiar words from the stimuli. The participants were asked to fit the words into one of four levels of word knowledge: (1) I never saw it before, (2) I've heard of it, but I don't know what it means, (3) I recognize it - it has something to do with . ..., and (4) I know it.

Then, the scale was analyzed and those words which were familiar to the participants were eliminated from the materials. It needs to be mentioned that the target words were purposefully blended with other easier words which were known to the participants. The reason for such a measure was that if the participants had only been given the unknown sound symbolic and non-sound symbolic words, they would have become frustrated and bored with the task. Hence, the unknown words were blended with less difficult known words so that they would be satisfied with the task.

\subsection{Presenting Stimuli in the Absence of Context}

Having checked the novelty of the stimuli and having eliminated the familiar words from the list of the selected words, the researchers presented the study stimuli to the intact groups. In this phase of the study, decontextualized non-sound symbolic words were given to the control group and decontextualized sound symbolic words were given to the experimental group. Indeed, the distinguishing feature in the given materials was sound symbolism. In other words, while one intact class was given unknown non-sound symbolic words in isolation, the second intact class was given unknown sound symbolic words in isolation. Within both intact groups, the participants were asked to guess the meaning of the unknown words which isolated from their context and choose one of the four choices for the given word. Therefore, non-sound symbolic words were given to the independent groups under two conditions: in the absence of context and in the presence of context.

Then, the papers were collected by the researchers and were scored until the next session of the class. In this phase of the study, the participants were not supposed to utilize the sound symbolic feature to guess the meaning of the words. The rationale for the inclusion of non-sound symbolic words in the materials was to compare the participants' guessing ability on two categories of words, i.e. sound symbolic and non-sound symbolic words. The results were analyzed both within the groups and between the groups. In other words, the performance of the intact groups in guessing the meaning of non-sound symbolic unknown words was designed to be compared with performance on sound symbolic words.

\subsection{Presenting Sound Symbolic Stimuli}

An important issue at stake was to investigate whether sound symbolism can make a difference in learning word meaning; hence, the procedures involved the participants to guess the meaning of sound symbolic and non-sound symbolic words under two conditions: in isolation and in context. Also, context was another significant variable which was manipulated. Indeed, isolated sound symbolic words were given to one independent group and isolated non-sound symbolic words were given to the second independent group. 
In the second phase of the study, context was also included in the materials. The participants were asked to guess the meanings of the words in context and choose one of the four choices. In this phase, the critical issue under investigation was to examine whether the participants in the first group (operationalized as the combination of context and sound symbolism) outperform the other group (operationalized as context in the absence of sound symbolism) in guessing the meaning of novel words. It should be contended that no specific instructional treatment was given to the groups. In other words, the participants were supposed to guess the meanings of the words on the basis of the given clues, context and/or sound symbolism.

\section{Findings}

4.1 Rating the Novelty of Word Stimuli

A crucial assumption for the validity of giving the study stimuli was their novelty; that is, vocabulary was designed to be novel and unknown for the participants. Hence, Dale et al's (1986) four-level scale of word knowledge was translated into the participants' official language (Farsi) and was given to them so as to check their initial knowledge of the selected stimuli (sound symbolic and non-sound symbolic vocabulary). The degree of novelty and unfamiliarity of all the vocabulary were tested by means of the mentioned scale; in other words, the participants were asked to produce evaluations of their degree of familiarity of the word stimuli on a four-point rating scale.

After the scale was administered, each response was assigned a number and the participants' rankings were used to exclude the vocabulary for which the participants had chosen items three and four but all the vocabulary ranked with the first and second choices were included as the targets of the study. Both sound symbolic and non-sound symbolic words were rated via the scale. The following table shows the participants' ranking of the novelty of both sound symbolic and non-sound symbolic words.

Table 1 . Degree of the novelty of vocabulary stimuli for participants

\begin{tabular}{|c|c|c|c|}
\hline \multirow{2}{*}{ Words } & \multicolumn{2}{|c|}{ Word Type } & \multirow{2}{*}{$\begin{array}{l}\text { Degree of } \\
\text { Novelty }\end{array}$} \\
\hline & $\begin{array}{l}\text { Sound } \\
\text { Symbolic }\end{array}$ & $\begin{array}{c}\text { Non- } \\
\text { Sound } \\
\text { Symbolic } \\
\sqrt{ }\end{array}$ & \\
\hline \multicolumn{4}{|c|}{ Contagious } \\
\hline & & $\sqrt{ }$ & 1 \\
\hline \multicolumn{4}{|l|}{ Excel } \\
\hline \multicolumn{3}{|l|}{ Delinquent } & 2 \\
\hline \multicolumn{4}{|l|}{ Refrain } \\
\hline \multicolumn{3}{|c|}{ Manipulate } & 2 \\
\hline Signify & & $\sqrt{ }$ & 1 \\
\hline Recline & & $\sqrt{ }$ & 1 \\
\hline Magnify & & $\sqrt{ }$ & 1 \\
\hline Ventilate & & $\sqrt{ }$ & 1 \\
\hline Quench & $\sqrt{ }$ & & 1 \\
\hline Clacker & $\sqrt{ }$ & & 1 \\
\hline $\begin{array}{l}\text { Growl } \\
\text { Gleam }\end{array}$ & $\sqrt{ }$ & & 1 \\
\hline $\begin{array}{c}\text { Splash } \\
\text { Bang }\end{array}$ & $\begin{array}{l}\sqrt{ } \\
\sqrt{ } \\
\sqrt{ }\end{array}$ & & $\begin{array}{l}1 \\
2 \\
1\end{array}$ \\
\hline $\begin{array}{l}\text { Quack } \\
\text { Clunk }\end{array}$ & $\sqrt{ }$ & & 1 \\
\hline Flicker & $\sqrt{ }$ & & 1 \\
\hline Crunch & $\sqrt{ }$ & & \\
\hline
\end{tabular}




\subsection{Research Question 1}

The first research question asked whether intermediate EFL learners can guess the meaning of unknown sound symbolic words significantly better than the meaning of unknown non-sound symbolic words when there is no surrounding written context. In other words, it was concerned with the capability of the participants to guess the meaning of unknown words with the aid of sound symbolism in the absence of context.

Having checked the novelty of the selected sound symbolic and non-sound symbolic words, the researchers gave the test. In order to answer the first research question and test the related hypothesis, the researchers gave the sound symbolic words to the experimental group and the non-sound symbolic counterpart to the control group. The researchers asked them to guess the meaning of the words and select one of the four choices for the meanings of the words. The participants of both groups were asked to guess the meaning of the words and select one of the given Farsi translations which followed each novel word. The researchers did not expect the participants to write the exact meaning of each word in English or Farsi; however, the purpose was to examine if the phonological make-up of sound symbolic words could help them to interpret the meaning of the words. The participants were not obliged to define the meaning of the words in English and the simple reason for this is that the ability to define the meaning of the words in English would be beyond their proficiency level and could be over-demanding for the participants. Instead, they were asked to relate the meaning of the given words to one of the four given Farsi translations which followed the items. It should be noted that while giving the test to the participants of the experimental group, the researchers asked them to note the makeup of the words for guessing their meaning. Indeed, the researchers tried to give the participants a hint and see whether they can use the pronunciation of the word in deciphering its meaning. The researchers followed the same procedures for both the experimental and control groups. However, the distinctive feature of the two independent groups was the type of the given words; decontextualized non-sound symbolic words were given to the first group and decontextualized sound symbolic words were given to the control group.

After giving the decontextualized materials (sound symbolic and non-sound symbolic words) to the participants within their groups, the researchers scored the participants' guesses as to the meanings of the unknown words and then fed the results into the SPSS for further statistical analysis. The researchers added some easy words to the guessing test so that the test would include some known words for the participants. The logical justification for the inclusion of non-target vocabulary to the targeted vocabulary was that the participants would be frustrated and bored if all the vocabulary were unknown to them. However, those words were excluded from the analysis. The following table shows the descriptive statistics for the results within each of the independent groups of the study.

Table 2. Descriptive statistics for decontextualized sound symbolic and non-sound symbolic words

\begin{tabular}{cccc}
\hline Groups & Mean & S. Deviation & Variance \\
\hline Sound symbolic Group & 8 & 1.460 & 2.132 \\
Non-sound symbolic group & 6 & 1.388 & 1.927 \\
\hline
\end{tabular}

As the table illustrates, sound symbolic group refers to the independent experimental group to which decontextualized sound symbolic words were given and non-sound symbolic group refers to the independent group to which decontextualized non-sound symbolic words were given. The second column in the table above shows the mean score for guessing the meaning of sound symbolic words within the sound symbolic group and guessing the meaning of nonsound symbolic words within the non-sound symbolic group. As the table descriptively illustrates, the mean score for guessing unknown words within the sound symbolic group (8) is higher than the mean score for guessing the unknown words within the non-sound symbolic group (6). However, the apparent descriptive difference in mean scores for guessing sound symbolic and non-sound symbolic words is not convincingly enough to claim that intermediate level participants can guess the meaning of sound symbolic words significantly better than non-sound symbolic words. Therefore, the researchers were obliged to statistically demonstrate, through inferential statistics, that the sound symbolic group guessed the meanings of sound symbolic words significantly better than non-sound symbolic group. For this reason, the researchers administered the independent sample $\mathrm{T}$-test to examine whether the difference between the mean scores is statistically significant or not. The following table demonstrates the results of the independent sample Ttest for checking the significance of difference between the two groups for guessing the meaning of sound symbolic and non-sound symbolic words. The below table shows the inferential statistics for substantiating the significance of difference between the groups. Independent sample T-test was used to compute the required inferential statistics.

Table 3. Independent sample T-test results for checking the significance of difference between groups

\begin{tabular}{cccccc}
\hline & Mean Difference & Std Error of mean & T & Df & Sig. \\
\hline \multirow{2}{*}{ Between Group } & 2 & 1.655 & \multirow{2}{*}{6.633} & 88 & \multirow{2}{*}{.000}
\end{tabular}

The above table reveals that the difference between the sound symbolic and non-sound symbolic groups in guessing the meaning of sound symbolic and non-sound symbolic words is significant with at least $95 \%$ of non-chance results. Since 
the $\mathrm{P}$ value in the table is less than .05 , hence, the null hypothesis derived from the first research question is rejected and the first alternative hypothesis is accepted.

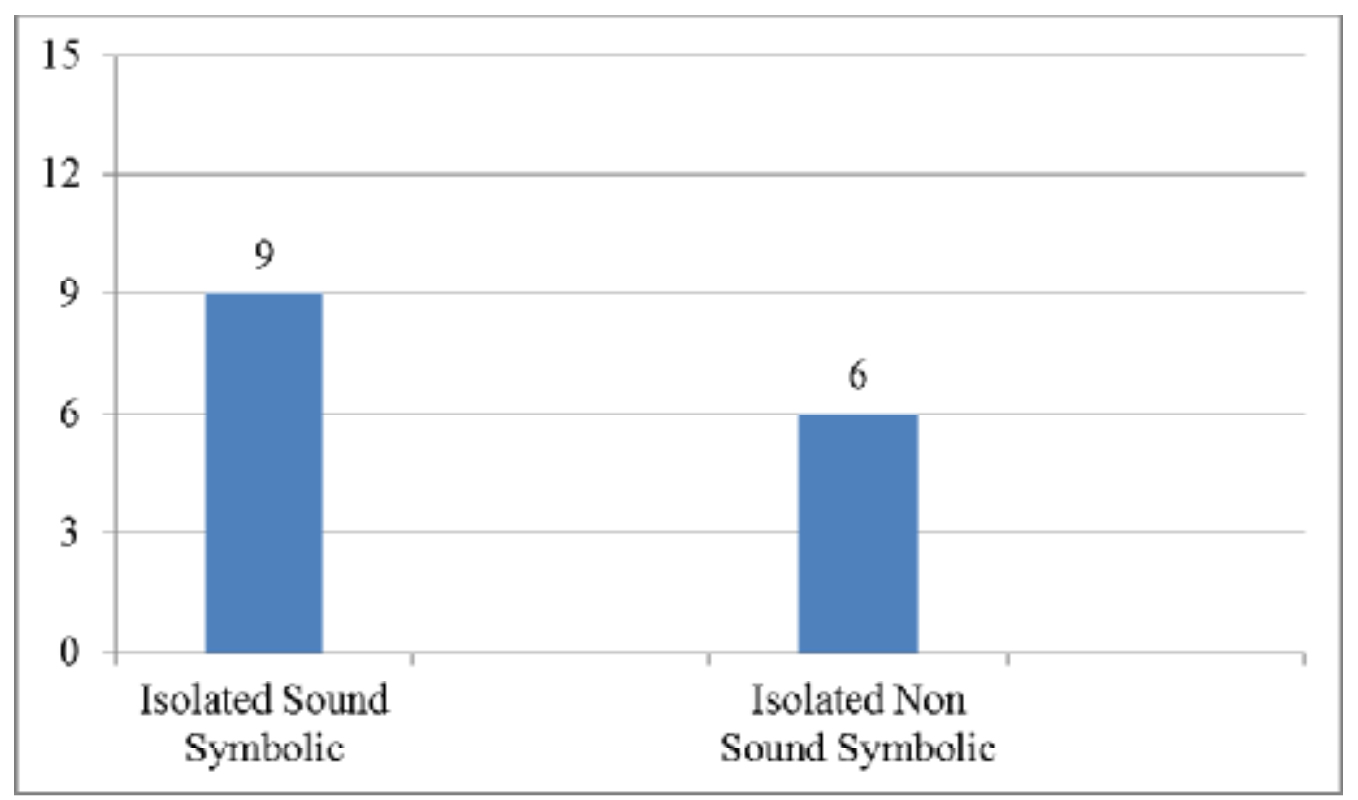

Figure 1. The difference between groups in guessing decontextualized sound symbolic and non-sound symbolic words

As the above figure illustrates, the degree of difference between the two groups in guessing the meaning of sound symbolic and non-sound symbolic words is equal to three. The logical interpretation for this difference is that the experimental group (sound symbolic group) guessed the meanings of sound symbolic words significantly better than the control group (non-sound symbolic group) for non-sound symbolic words. This finding is consistent with the literature on sound symbolism. In other words, this finding verified the efficacy and role of sound symbolism as a word level property for learning the meanings of words. The statistical analysis of the collected data provides a positive answer to the first research question. As a matter of fact, the researchers can argue that EFL learners can utilize the sound structure of words, in case of sound symbolic words, to constrain their meanings. Therefore, the present study corroborates the potential efficacy of sound symbolism for guessing the meaning of new lexical items and as a result the alternative hypothesis which was formulated for the first research question is admitted.

\subsection{Research Question 2}

The second research question asked whether intermediate EFL learners can guess the meaning of unknown sound symbolic words significantly better than the meaning of unknown non-sound symbolic words when they are embedded in and surrounded by context.

In order to answer this research question, the researchers had to introduce another variable, i.e. context, into the materials. In other words, the efficacy of guessing sound symbolic and non-sound symbolic words in isolation was investigated in the first research question. Hence, the second research question involved both sound symbolism and context as the variables of focus. The researchers embedded sound symbolic and non-sound symbolic words in their relevant context (sentence) in order to test the second research question. In this phase of the study, the unknown sound symbolic words were embedded in context and were given to the experimental group and likewise the contextualized unknown non-sound symbolic words were given to the control group. The participants within the sound symbolic group were asked to try to notice the sound structure of the words to guess their meanings. This was done to make them notice the phonological structure of the words as a clue for better decoding and interpreting their meanings. The following table shows the results for guessing the meanings of unknown sound symbolic and non-sound symbolic words in context.

Table 4. Descriptive statistics for contextualized sound symbolic and non-sound symbolic words

\begin{tabular}{lrcc}
\hline Groups & Mean & S. Deviation & Variance \\
\hline Contextualized Sound symbolic Group & 11 & 3.17 \\
Contextualized non-sound symbolic group & 9 & 3.23 \\
\hline
\end{tabular}

As the table indicates, the contextualized sound symbolic group outperformed the contextualized non-sound symbolic group. That is, the mean score (11) for the participants who correctly guessed the meanings of contextualized sound symbolic words was descriptively higher than the mean score (9) for the participants who correctly guessed the meanings of non-sound symbolic words in context. However, inferential statistics should be used to substantiate that the difference between the mean scores of the experimental and control groups is significant. The following table shows the inferential statistics for calculating the independent sample t-test. 
Table 5. Independent sample T-test for significance of difference between contextualized sound symbolic and non-sound symbolic groups.

\begin{tabular}{cccccc}
\hline & Mean Difference & Std Error of mean & T & Df & Sig. \\
\hline \multirow{2}{*}{ Between Group } & 2 & 1.655 & 6.633 & 88 & .000 \\
\hline
\end{tabular}

As the above table shows, the difference between the two independent groups in guessing the meaning of contextualized sound symbolic and non-sound symbolic words is statistically significant with $95 \%$ of non-chance results. Inasmuch as the $\mathrm{P}$ value is less than .01, the researchers can reject the second null hypothesis and accept the second alternative hypothesis. The following figure demonstrates the performance of the experimental and control groups in guessing the meaning of contextualized stimuli.

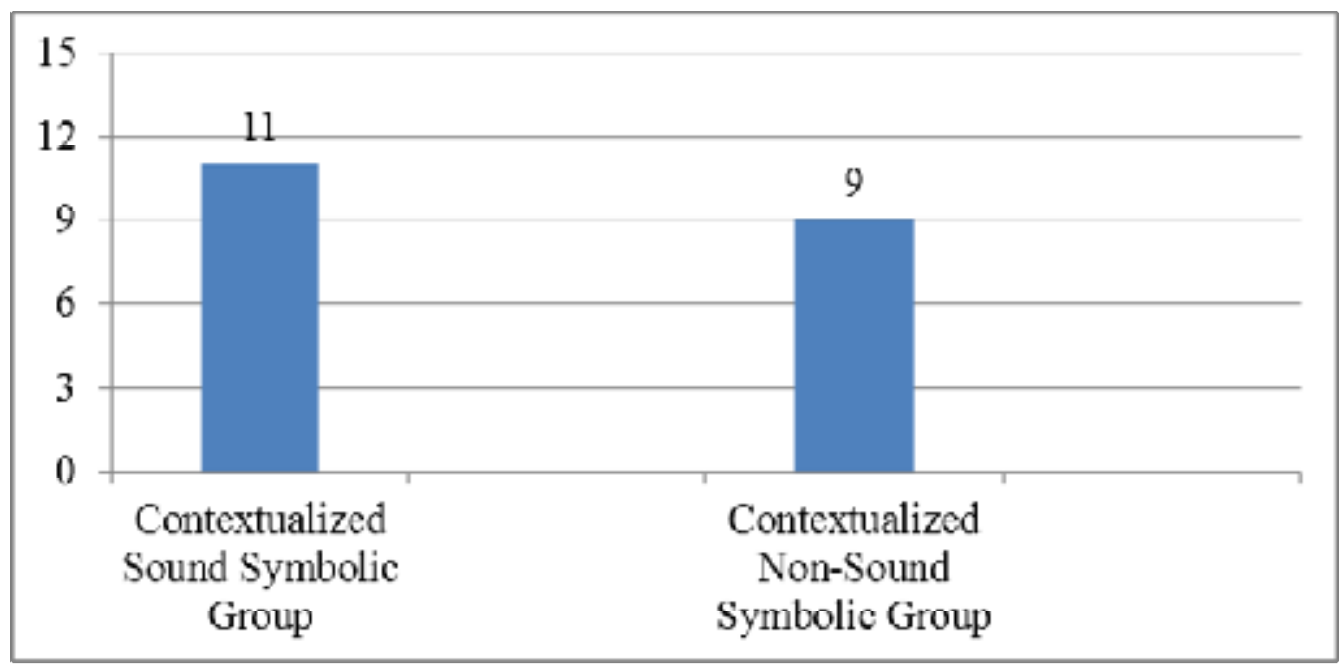

Figure 2. The difference between the groups in guessing decontextualized sound symbolic and non-sound symbolic words

As the above figure demonstrates, the performance of the first group is higher than that of the second group. Indeed, the efficacy of the both variables of sound symbolism and context was beyond that of context alone. In simple terms, the combination of the two variables of context and sound symbolism which was present in the study stimuli of the experimental group helped them guess the meanings of contextualized sound symbolic words significantly better than the control group which guessed the meanings of contextualized non-sound symbolic words. As a matter of fact, the presence of sound symbolism provides the rational explanation for the significantly higher mean score of one group over the other group. Consequently, the second null hypothesis of the study which was derived from the second research question is rejected and the second alternative hypothesis is accepted.

\subsection{Research Question 3}

This research question asked whether sound symbolism as a hypothetical word property interact with context so as to provide intermediate EFL learners with a significantly richer clue than that merely provided by context alone for guessing the meaning of sound symbolic words.

In order to answer this research question and test the relevant hypothesis, the researchers drew upon the same data which was used for the second research question of the study. In other words, the third research question was related to the second research question in that it zoomed in on the effectiveness of using context as well as sound symbolism as a word property. The following table and figure show the characteristics of the study stimuli which were given to the independent groups of study.

Table 6. Different combinations and interaction of the variables given to the groups

\begin{tabular}{c|c|c|c}
\hline Context & Coniables & $\begin{array}{c}\text { Sound } \\
\text { symbolism }\end{array}$ & $\begin{array}{c}\text { Results: } \\
\text { Mean score } \\
\text { out of } 15\end{array}$ \\
\hline 1 & -- & -- & $6 / 15$ \\
\hline 2 & -- & $\sqrt{ }$ & $8 / 15$ \\
\hline 3 & $\sqrt{ }$ & $\sqrt{ }$ & $9 / 15$ \\
\hline 4 & & & $11 / 15$ \\
\hline
\end{tabular}

* Total score: 15 
The above table illustrates the presence or absence of the two independent variables of the study in the given stimuli. The two independent groups underwent four different conditions from one to four as shown in the table. The following figure demonstrates the conditions.

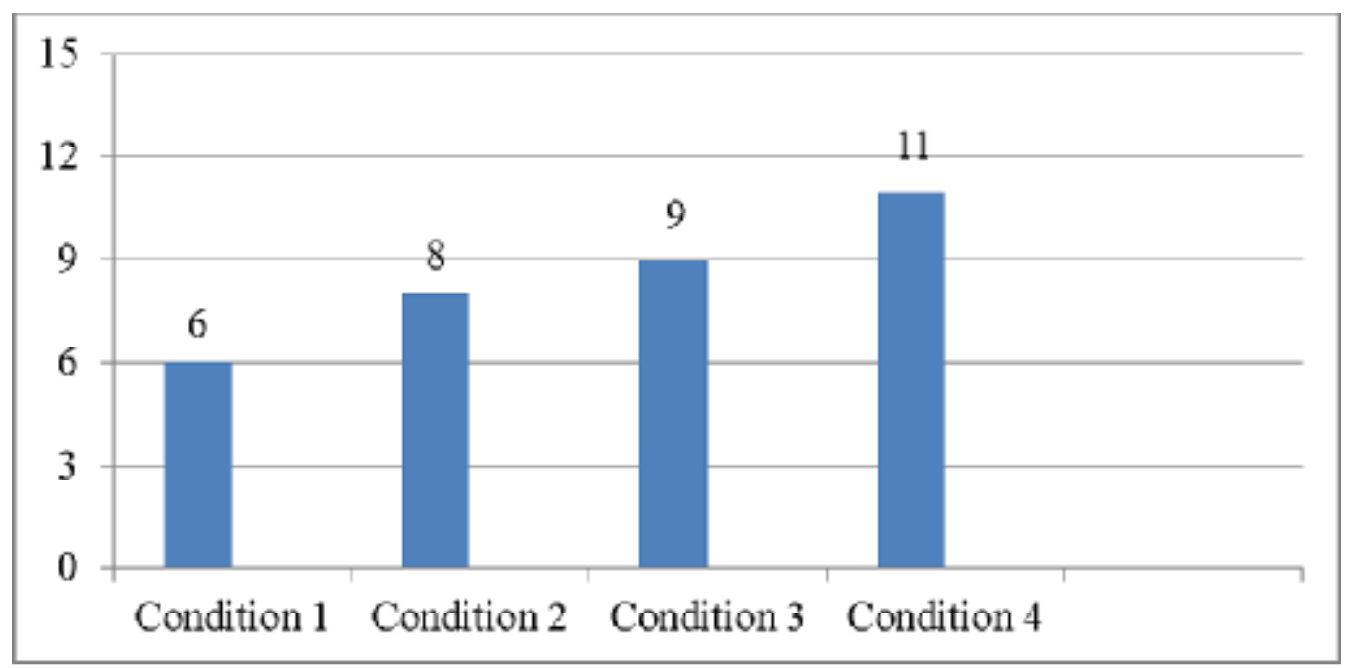

Figure 3. The results for different conditions and combinations of the variables

In the first condition, neither context nor sound symbolism was included in the given vocabulary which resulted in the mean score of six for the control group. In the second condition, sound symbolic words were given in isolation; that is, one of the two independent variables was present in the word stimuli which resulted in the mean score of eight for the experimental group. Under the third condition, the word stimuli were given in context but they were non-sound symbolic words which resulted in the mean score of nine for the control group of the study. Finally, the forth condition involved the combination of both variables, i.e. sound symbolism and context in the word stimuli which had the highest result for the participants. In fact, the inclusion of both variables positively impacted on constraining the meaning of the unknown words for the participants. Therefore, according to the preceding table and figure, the results of the study indicate that including both sound symbolism and context had the best results in comparison with the conditions in which one of the two variables was included.

It can be argued that sound symbolism interacted with context and hence the presence of both variables improved the guessing ability for the participants. As the last column of the above table shows, the interactive efficacy of the two variables (sound symbolism plus context) is higher than the efficacy of either variable. As a result, the answer to the third question is positive and consequently the third alternative hypothesis is accepted.

\section{Discussion and Conclusion}

Sound symbolism was introduced in this study as a term for a speculative non-arbitrary relationship between sound and meaning. It is considered to be an issue which lies at the heart of theoretical linguistics. Certain correspondences between the sound and meaning of words were observed in subsets of vocabulary.

Indeed, as Parault and Schwanenflugel (2006) aptly argue, sound symbolism should be considered as a piece in the puzzle of word learning. The results of the present study corroborated the findings of Parault and Schwanenflugel (2006) that sound symbolism is a word level property that influences word learning.

In sum, the results of the study show that the sample EFL learners made use of sound symbolism to restrict the meaning of unknown words. However, the research into sound symbolism from an applied linguistic aspect is in its infancy and more research needs to be conducted on this issue to uncover its potentials for second language acquisition.

The conclusion to be made from the present study is that sound symbolism seems to be more than phonology as it carries meaning but less than morphology because the one-to-one relationship between sound and meaning is not as strong or stable. Sound symbolic information in words seems to influence word processing. Inasmuch as EFL learners may not generally notice this linguistic feature systematically, they need to be sensitized to this feature and their awareness should be raised so that they make use of it in guessing the meaning of unknown words. It can be deduced that any kind of strategy that can help narrow down the possible meaning of a word is useful to word learners.

Sound symbolism can be used as a strategy to narrow down the possible meaning of words. It can help word learning in the absence of contextual information. The truth is that teachers hardly use sound symbolism as a word level property for learning the meaning of words. Sound symbols are similar to morphemes in that they carry meaning and allow for word learning in the absence of contextual information. EFL teachers can teach learners to use the available sound symbolic information on words to facilitate lexical and semantic processing. Indeed, EFL teachers can guide learners to use iconic representations as a word level clue along with other contextual strategies or independently of them to guess the meaning of unknown words. Sound symbolism might be a strategy like morphological analysis that teachers can instruct EFL learners to use.

\section{References}

Abelin, A. (1999). Studies in sound symbolism. Gothenburg Monographs in Linguistics 17. Gothenburg, 279 sid. Astika, G. (1993). Analytical assessments of foreign students' writing. RELC Journal, 24, 61-70. 
Austerlitz, R. (1994). Finnish and Gilyak sound symbolism - an interplay between system and history. In L. Hinton, J. Nichols \& J.J. Ohala (Eds.), Sound symbolism (pp. 249-260). Cambridge: CUP.

Berlin, B. (1994). Evidence for pervasive synesthetic sound symbolism in ethnozoological nomenclature. In L. Hinton, J. Nichols \& J. Ohala (Eds.), Sound Symbolism (pp. 76-93). New York: CUP.

Carter, R. (2001). Vocabulary. In R. Carter \& D. Nunan (Eds.), Teaching English to speakers of other languages (pp. 72-79). Cambridge: CUP.

Dale, E., O’Rourke, J., \& Barbe, W. B. (1986). Vocabulary building: A process approach. Columbus, OH: ZanerBloser.

Elgort, I. \& Nation, I.S.P. (2010). Vocabulary learning in a second language: Familiar answers to new questions. In P. Seedhouse, S. Walsh \& C. Jenks (Eds.), Conceptualizing learning in applied linguistics. Houndmills: Macmillan.

Engber, C. (1995). The relationship of lexical proficiency to the quality of ESL compositions. Journal of Second Language Writing, 4, 213-238.

Hinton, L., Nichols, J. \& Ohala, J. J. (1994). Sound symbolism. New York: CUP.

Hulstijn, J., \& Laufer, B. (2001). Some empirical evidence for the involvement of load hypothesis in vocabulary acquisition. Language Learning, 51(3), 539-558.

Imai, M., Kita, S., Nagumo, M., \& Okada, H. (2008). Sound-symbolism between a word and an action facilitates early verb learning. Cognition, 109, 54-65.

Kunihara, S. (1971). Effects of the expressive voice on phonetic symbolism. Journal of Verbal Learning and Verbal Behavior, 10, 427-429.

Laufer, B. (1991). Some properties of the L2 mental lexicon as evidenced by lexical confusions. International Review of Applied Linguistics, 29(2), 317-330.

Laufer, B. (1997).What's in a word that makes it hard or easy? Some intralexical factors that affect the learning of words. In N. Schmitt \& M. McCarthy (Eds), Vocabulary description: Description, acquisition and pedagogy (pp. 140155). Cambridge: CUP.

Nation, P. (2002). Best practice in vocabulary teaching and learning. In J. C. Richards \& W. A. Renandya (Eds.), Methodology in language teaching: An anthology of current practice (pp. 267-272). Cambridge: CUP.

Nuckolls, J. B. (1999). The case for sound symbolism. Annual Review of Anthropology, 28, 225-252.

Parault, S. J. \& Schwanenflugel, P. J. (2006). Sound symbolism: A piece in the puzzle of word learning. Journal of Psycholinguistic Research, 35, 329-351.

Sereno J. A. (1994). Phonosyntactics. In L. Hinton, J. Nichols \& J. Ohala (Eds.), Sound Symbolism. New York: CUP. Ultan, R. (1978). Size-sound symbolism. In J. Greenberg (Eds.), Universals of human language (pp. 525-568). Stanford, California: Stanford University Press. 